\title{
O Mapa Conceitual como ferramenta de ensino e aprendizagem significativa sobre o Sistema Único de Saúde
}

The Conceptual Map as a tool for teaching and meaningful learning about the Unified Health System

El mapa conceptual como una herramienta de enseñanza y aprendizaje significativo en el Sistema de Salud

Rosângela Minardi Mitre Cotta ${ }^{1}$, Luciana Saraiva da Silva ${ }^{2}$, Rodrigo Mitre Cotta ${ }^{3}$, Fernanda Mitre Cotta $^{4}$, Mariana Araújo Pena Bastos ${ }^{5}$, Aline Aparecida de Oliveira Campos ${ }^{6}$, Juliana Costa Machado $^{7}$

\section{Resumo}

O Mapa Conceitual (MC) destaca-se como metodologia ativa de ensino, aprendizagem e avaliação, estimula a participação do educando, desenvolvendo a autonomia e o comprometimento no processo de aprendizagem. O objetivo deste estudo foi apresentar um relato de experiência do uso do MC como ferramenta de ensino e aprendizagem significativa sobre o Sistema Único de Saúde (SUS), visando o exercício do aprender a aprender, a conhecer e a conviver. Trata-se de uma pesquisa qualitativa, que utilizou como método, o estudo de caso, tendo como referência os estudantes de graduação da área da saúde que cursaram a disciplina de Políticas de Saúde, nos semestres letivos dos anos de 2014, 2015 e 2016. A coleta dos dados ocorreu por meio da análise documental e depoimentos dos estudantes. A análise e o tratamento dos dados se deram por meio da análise temática. Segundo o depoimento dos estudantes participantes do estudo, o MC facilitou o aprendizado, propiciou a conexão entre os conteúdos, promoveu a compreensão dos conceitos chave, estimulou o pensamento crítico-reflexivo, o trabalho em equipe, a criatividade, a autonomia e o empoderamento, e promoveu a capacidade de análise e síntese, tornando o estudo dinâmico. Como fatores negativos, os estudantes apontaram a dificuldade no uso do programa CMapTools e

${ }^{1}$ Doutora em Saúde Pública pela Universidad de Valencia, Espanha. Professora Associada do Departamento de Nutrição e Saúde da Universidade Federal de Viçosa (UFV). Avenida P.H. Rolfs, s/n, Campus Universitário, Viçosa, Minas Gerais, Brasil, CEP: 36571-000. Email: rosangelaminardi@hotmail.com

2 Mestre em Ciência da Nutrição pela Universidade Federal de Viçosa (UFV). Doutoranda do Programa de PósGraduação em Ciência da Nutrição da UFV. Avenida P.H. Rolfs, s/n, Campus Universitário, Viçosa, Minas Gerais, Brasil, CEP: 36571-000. E-mail: lucianassnut@gmail.com

${ }^{3}$ Médico pela Faculdade de Medicina de Barbacena (FUNJOBE), Barbacena, Minas Gerais. Residente de Ortopedia e Traumatologia no Hospital Santa Casa de Misericórdia de Belo Horizonte. Avenida P.H. Rolfs, s/n, Campus Universitário, Viçosa, Minas Gerais, Brasil, CEP: 36571-000. Email: rodrigomcotta@ hotmail.com

${ }^{4}$ Médica pela Faculdade de Medicina de Barbacena (FUNJOBE), Barbacena, Minas Gerais, Brasil. Residente de Ginecologia e Obstetrícia no Hospital Sofia Feldman. Avenida P.H. Rolfs, s/n, Campus Universitário, Viçosa, Minas Gerais, Brasil, CEP: 36571-000. Email: fernandamitrec@ hotmail.com

${ }^{5}$ Mestre em Ciência da Nutrição pela Universidade Federal de Viçosa (UFV). Pesquisadora do Programa de Inovação em Docência Universitária - PRODUS/UFV. Avenida P.H. Rolfs, s/n, Campus Universitário, Viçosa, Minas Gerais, Brasil, CEP: 36571-000. E-mail: marianaapbastos@gmail.com

${ }^{6}$ Mestre em Ciência da Nutrição pela Universidade Federal de Viçosa (UFV). Doutoranda do Programa de PósGraduação em Ciência da Nutrição da UFV. Avenida P.H. Rolfs, s/n, Campus Universitário, Viçosa, Minas Gerais, Brasil, CEP: 36571-000. E-mail: alinecamposufv@gmail.com

${ }^{7}$ Doutora em Ciência da Nutrição pela Universidade Federal de Viçosa (UFV). Pesquisadora do Programa de Inovação em Docência Universitária - PRODUS/UFV. Avenida P.H. Rolfs, s/n, Campus Universitário, Viçosa, Minas Gerais, Brasil, CEP: 36571-000. E-mail: juboechat@yahoo.com.br 
ISSN 2179-6750

os aspectos relacionados à demanda de tempo para sua construção.

Descritores: Mapa Conceitual, Método Ativo, Educação em Saúde, Sistema Único de Saúde, Aprendizagem Significativa.

\begin{abstract}
The Concept Map (CM) stands out as active methodology of teaching, learning and assessment, encourages the participation of the student, developing autonomy and commitment in the learning process. The aim of this study was to present an experience report of the use of CM as a teaching and meaningful learning tool on the Sistema Único de Saúde (SUS), to the exercise of learning to learn, to know and to live. This is a qualitative study, which used the case study as a method, with reference to health undergraduate students who attended the discipline of Health Policy, the academic semesters of the years 2014, 2015 and 2016. Data collection occurred through document analysis and interviews of students. The analysis and processing of the data is given through the thematic analysis. According to the students, the CM facilitated learning, provided the connection between the content, promoted understanding of key concepts, stimulated critical and reflective thinking, teamwork, creativity, autonomy and empowerment, and promoted the ability of analysis and synthesis, making the dynamic study. As negative factors, the students pointed out the difficulty in using CmapTools program and aspects related to the time required for its construction.
\end{abstract}

Key-words: Concept Map, Active Method, Health Education, Health System, Meaningful Learning.

\title{
Resumen
}

El mapa conceptual (MC) es una metodología activa de enseñanza, aprendizaje y evaluación, fomenta la participación del estudiante, el desarrollo de la autonomía y la participación en el proceso de aprendizaje. El objetivo de este estudio es presentar el uso del MC como una herramienta de enseñanza y aprendizaje significativo en el Sistema Único de Saúde (SUS), para el ejercicio de aprender a aprender, a conocer y vivir. Se trata de un estudio cualitativo, que utilizó como método el estudio de caso, con referencia a los estudiantes universitarios que asistieron a la disciplina "Política de Salud", en los años 2014, 2015 y 2016. Los datos se produjo a través del análisis de documentos y entrevistas con los estudiantes. El análisis y procesamiento de los datos se dan a través del análisis temático. De acuerdo con los estudiantes que participaron del estudio, el MC facilitó el aprendizaje, la conexión entre el contenido, promovió la comprensión de los conceptos clave, estimuló el pensamiento crítico y reflexivo, el trabajo en equipo, la creatividad, la autonomía y la potenciación, y ha promovido la capacidad de análisis y síntesis, por el estudio dinámico. Como factores negativos, los estudiantes señalaron la dificultad en el uso del programa CMapTools y aspectos relacionados con el tiempo requerido para su construcción

Palabras-claves: Mapa Conceptual, Método Activo, Educación Sanitaria, Sistema de Salud, Aprendizaje Significativo.

\section{Introdução}

No mundo atual, as transformações das sociedades contemporâneas salientam sobre a importância do desenvolvimento de uma visão sistêmica da formação e educação profissional. Segundo Cotta et al. ${ }^{1}$, na saúde, estas transformações vêm ganhando contornos próprios quando se 
ISSN 2179-6750

coloca em cheque a estrutura curricular tradicional, pobre em integrar teoria e prática, cada vez mais especializada e dissociada das preocupações sociais. Historicamente, os profissionais de saúde têm recebido uma formação baseada em metodologias de ensino e aprendizagem conservadoras (tradicionais), sofrendo forte influência do mecanicismo de inspiração cartesiana-newtoniana, fragmentado e reducionista.

Neste contexto, as atuais mudanças exigidas no processo de formação dos profissionais de saúde requerem a articulação de conhecimentos, habilidades e atitudes (competências), respeitando a diversidade, a formação ética, humanística, valorizando a integração de saberes e a articulação destes com a realidade vivida no cotidiano das pessoas. Assim, no Brasil, o novo paradigma de ensino-aprendizagem proposto pelas Diretrizes Curriculares Nacionais (DCN) ${ }^{2}$, objetiva transferir o foco do ensino tradicional centrado no professor, no conteúdo e na memorização, para o ensino centrado no processo de aprendizagem, com estímulo ao aprendizado autônomo, ativo, criativo e crítico-reflexivo. Tal proposta requer uma transformação profunda do ensino universitário, resultando em mudanças de papeis dos agentes envolvidos (docentes e discentes) implicando-os e responsabilizando-os $1,3,4,5$.

A proposta é formar os futuros profissionais para atuarem na Política de saúde brasileira, o Sistema Único de Saúde (SUS), considerando as necessidades de saúde individuais e coletivas e reorientando o modelo assistencial, de forma a valorizar a promoção da saúde e prevenção de agravos e enfermidades, salientando os determinantes sociais ${ }^{1}$.

Sob essa ótica, têm sido recomendadas mudanças pedagógicas, as quais começam a configurar um novo paradigma de ensino, com intuito de (trans)formar o estudante em um profissional crítico, reflexivo e capaz de, na sua prática, tomar decisões e solucionar problemas $1,4,5,6$.

De entre as várias propostas de métodos ativos de ensino, aprendizagem e avaliação, destaca-se o Mapa Conceitual (MC), por apresentar uma abordagem pedagógica que estimula a participação do educando, desenvolvendo a autonomia e o comprometimento individual e coletivo no processo de aprendizagem.

O MC foi desenvolvido como uma ferramenta gráfica para organizar e representar o conhecimento com o objetivo de proporcionar maior compreensão e assimilação sobre o tema de estudo ${ }^{7}$. O pressuposto conceitual para o emprego do MC é a teoria da aprendizagem significativa, do construtivista David Ausubel ${ }^{8}$, a qual propõe que para um aprendizado mais eficiente é necessário que o conhecimento seja (1) compreendido, (2) significativamente relevante e (3) bem integrado. Assim, a aprendizagem significativa consiste na integração de novos conceitos à estrutura 
ISSN 2179-6750

cognitiva do estudante, considerando o seu conhecimento pré-existente, com o propósito de estabelecer aprendizagens interrelacionadas, o que facilita o estabelecimento de associações conceituais sólidas ${ }^{9}$. Um dos principais potenciais da utilização dos MC para os cursos da área de saúde é a possibilidade de integrar diferentes conceitos, uma vez que a sua construção possibilta as conexões existentes entre a temática abordada, a revisão de ideias e a organização do conteúdo de forma autônoma.

Destarte, o objetivo deste estudo foi apresentar um relato de experiência do uso do MC como ferramenta de ensino e aprendizagem significativa sobre o SUS, visando o exercício do aprender a aprender, a conhecer e a conviver.

\section{Métodos}

Estudo fundamentado pelo referencial teórico da pesquisa qualitativa, o qual utilizou como método o estudo de caso, modalidade de investigação empírica empregada quando se pretende buscar um conhecimento circunstanciado a respeito de um tema ${ }^{10}$, no caso deste trabalho, as Políticas de Saúde, com ênfase no SUS. A coleta dos dados se deu a partir da análise documental, cujos documentos foram os portfólios construídos em equipes e os depoimentos dos alunos sobre suas percepções do processo de aprendizado proporcionado pela experiência de construção coletiva do MC.

Os sujeitos da pesquisa foram os estudantes de graduação dos cursos da área da saúde da Universidade Federal de Viçosa (UFV), que cursaram a disciplina Políticas de Saúde durante 5 semestres letivos dos anos de 2014, 2015 e 2016, totalizando 236 alunos. Os MC foram construídos em equipes de 5 ou 6 alunos, tendo no período de estudo, 42 MC. As temáticas da disciplina em questão referem-se às Políticas de Saúde no Brasil e no mundo, abordando o processo histórico de formação das políticas sociais e de saúde, os diferentes paradigmas sanitários, as práticas sanitárias, os desenhos e modelos de políticas, as modalidades de proteção social, os tipos de cidadania, os determinantes estruturais, econômicos, políticos e sociais que repercutem sobre o processo saúdedoença-adoecimento, bem como suas implicações para a prática profissional referente ao cuidado, assistência e gestão em saúde. A referência teórica-conceitual foi o livro Políticas de Saúde: desenhos, modelos e paradigmas ${ }^{11}$.

A construção do MC pelos estudantes seguiu os seguintes passos: primeiramente os estudantes participavam de exposições dialogadas de determinada temática proferida pelos docentes da disciplina, (momento presencial); em seguida cada estudante tinha que elaborar individualmente uma síntese do capítulo em questão, destacando ao final os conceitos chave de cada capítulo 
ISSN 2179-6750

(momento à distância); na terceira etapa os estudantes em suas respectivas equipes (coletivamente), discutiam as sínteses individuais, construíam uma síntese coletiva, simultaneamente à construção do MC orientados pelos docentes (feedback presencial). Ao final da disciplina, os alunos apresentavam um único MC contendo todo o conteúdo da disciplina, ou seja, o MC era retomado e reconstruído gradativamente a cada conteúdo estudado. Desta forma, os estudantes faziam o exercício de incorporar novos conceitos, transformando os conceitos chave em conceitos secundários a medida que os conteúdos aprendidos ficavam mais completos e complexos. Para a construção do MC utilizou-se o programa CMapTools (momento presencial seguido de momento à distância). O CmapTools é uma ferramenta disponibilizada online e gratuitamente para elaborar esquemas conceituais e representá-los graficamente, ou seja, é um programa que auxilia a desenhar o MC. O próprio programa propicia a criação de caixas para que os estudantes escrevam os conceitos chave, e as relações entre eles são especificadas por meio de termos de enlace, que une um conceito ao outro, formando proposições.

A disciplina Políticas de Saúde tem uma carga horária total de 60 horas presenciais e é constituída de aulas teóricas com exposições dialogadas para 60 alunos (30 horas/semestre) e aulas práticas, sendo 3 turmas com 20 alunos cada (30 horas/semestre). Em relação às aulas práticas, 40\% destas eram destinadas à construção do MC. A pontuação do MC se refere a $20 \%$ do valor total da disciplina.

As temáticas da disciplina de Políticas de Saúde seguiram a ordem dos capítulos do livro de referência da disciplina: Políticas de Saúde: desenhos, modelos e paradigmas ${ }^{11}$. Após cada capítulo estudado e cumprido todos os passos relatados acima, as equipes de estudantes enviavam por e-mail o MC construído para uma avaliação pelos docentes que davam o feedback, tanto nos momentos presenciais de construção dos MC, como após o recebimento do MC por e-mail. Neste estudo, escolheu-se um MC desenvolvido no decorrer do período de estudo para ilustrar o processo de construção do MC pelos estudantes.

Para a avaliação do MC em cada fase do estudo das temáticas da disciplina de Políticas de Saúde, construiu-se um instrumento a partir da experiência dos autores e estudos presentes na literatura ${ }^{12-14}$. Este instrumento de avaliação foi testado, modificado e legitimado com os estudantes durante os semestres letivos (Figura 1). Seguindo os preceitos da avaliação formativa, foram 3 os momentos de avaliação do MC, sendo que a cada capítulo estudado, os estudantes iam se apropriando mais dos conceitos, princípios e mecanismos de funcionamento das Políticas de Saúde e, como consequência, os MC se modificavam e ganhavam mais consistência e significado. 
Figura 1. Instrumento de Avaliação do MC na disciplina Políticas de Saúde

\begin{tabular}{|c|c|c|c|c|c|c|}
\hline \multirow[t]{2}{*}{$\begin{array}{c}\text { Pontos a serem } \\
\text { avaliados }\end{array}$} & \multirow{2}{*}{$\begin{array}{c}\text { Avaliação pelos professores } \\
\text { / tutores } \\
\text { (Orientações realizadas } \\
\text { em sala de aula (momento } \\
\text { presencial) - devem ser } \\
\text { consideradas pelos } \\
\text { estudantes ao entregarem } \\
\text { o MC) }\end{array}$} & \multicolumn{4}{|c|}{$\begin{array}{l}\text { Incorporou as orientações realizadas em sala de } \\
\text { aula } \\
\text { (Momento presencial e à distância)? }\end{array}$} & \multirow[t]{2}{*}{ Total } \\
\hline & & Sim & Não & Parcial & $\begin{array}{c}\text { Justificativas } \\
\text { (detalhamento) }\end{array}$ & \\
\hline CONCEITOS ( 3,0 pontos $)$ & & & & & & \\
\hline $\begin{array}{l}\text { Presença de conceitos } \\
\text { equivocados (1,0 ponto) }\end{array}$ & & & & & & \\
\hline $\begin{array}{l}\text { Presença de conceitos chave } \\
\text { repetidos }(0,5 \text { ponto })\end{array}$ & & & & & & \\
\hline $\begin{array}{l}\text { Presença de mais de um } \\
\text { conceito chave na caixa de } \\
\text { texto ( } 1,0 \text { ponto })\end{array}$ & & & & & & \\
\hline $\begin{array}{l}\text { Presença de conceitos } \\
\text { secundários nas caixas de } \\
\text { textos }(0,5 \text { ponto })\end{array}$ & & & & & & \\
\hline $\begin{array}{c}\text { TERMOS DE ENLACE } \\
(2,0 \text { pontos })\end{array}$ & & & & & & \\
\hline $\begin{array}{c}\text { Presença de conceitos } \\
\text { chave nos termos de enlace } \\
(1,0 \text { ponto })\end{array}$ & & & & & & \\
\hline $\begin{array}{c}\text { Termos de enlace } \\
\text { inapropriados }(0,5 \text { ponto })\end{array}$ & & & & & & \\
\hline $\begin{array}{l}\text { Não utilização do termo de } \\
\text { enlace para formar } \\
\text { proposição }(0,5 \text { ponto })\end{array}$ & & & & & & \\
\hline $\begin{array}{l}\text { DEMAIS ASPECTOS } \\
\text { IMPORTANTES } \\
(6,0 \text { pontos })\end{array}$ & & & & & & \\
\hline $\begin{array}{l}\text { Proposições inadequadas } \\
\text { (frases equivocadas) }(1,0 \\
\text { ponto) }\end{array}$ & & & & & & \\
\hline $\begin{array}{c}\text { Relações cruzadas } \\
\text { inapropriadas }(1,0 \text { ponto) }\end{array}$ & & & & & & \\
\hline $\begin{array}{c}\text { Presença de sobreposição de } \\
\text { setas }(0,5 \text { ponto) }\end{array}$ & & & & & & \\
\hline $\begin{array}{l}\text { Capacidade de síntese } \\
\text { (trocar/excluir conceitos } \\
\text { chave à medida que os } \\
\text { conhecimentos sobre } \\
\text { Políticas de Saúde são } \\
\text { ampliados) (1,0 ponto) }\end{array}$ & & & & & & \\
\hline $\begin{array}{l}\text { Organização gráfica do } \\
\text { Mapa Conceitual (permite } \\
\text { uma visualização das } \\
\text { partes e do todo de forma } \\
\text { clara e coerente) ( } 1,0 \text { ponto) }\end{array}$ & & & & & & \\
\hline $\begin{array}{l}\text { O MC permite visualizar a } \\
\text { integração dos conteúdos } \\
\text { dos capítulos estudados? } \\
\text { Ou seja, à medida que } \\
\text { novos conceitos chave são } \\
\text { aprendidos estes são } \\
\text { integrados ao MC de } \\
\text { forma coerente e } \\
\text { harmônica, evitando a } \\
\text { fragmentação dos } \\
\text { conteúdos? (Ou constrói o } \\
\text { MC de forma fragmentada?) } \\
\text { (1,5 ponto) }\end{array}$ & & & & & & \\
\hline
\end{tabular}


ISSN 2179-6750

Utilizou-se ainda, a análise documental, cujos documentos foram os Portfólios coletivos reflexivos construídos também na disciplina Políticas de Saúde pelas mesmas equipes, concomitante à construção do MC. Segundo Cotta et al. ${ }^{4,5}$, os portfólios são instrumentos/estratégias de estímulo ao pensamento reflexivo, que consideram a educação a partir de uma perspectiva diferente - "se aprende o que se faz e o que se faz se aprende"; possibilitando a observação de um processo de maturação dos grupos por meio da ampliação de conceitos, conhecimentos, comportamentos e práticas ${ }^{15}$.

O foco de análise dos portfólios foram os depoimentos dos alunos referentes ao processo de construção do MC, destacando-se os tipos de aprendizagens relatadas, bem como as fragilidades e as fortalezas.

Inicialmente, realizou-se uma leitura flutuante dos portfólios para estabelecimento das categorias presentes no corpus documental. A análise e o tratamento dos dados se deram por meio da análise temática, com recorte do texto em unidades comparáveis, sob a forma de categorização. As categorias são classes que reúnem um grupo de elementos sob um título genérico agrupados em razão das características comuns. A categorização tem por finalidade fornecer uma representação simplificada dos dados brutos, que passam a dados organizados, e comportam duas etapas: o inventário, no qual os elementos são isolados; e a classificação, na qual os elementos são repartidos, ou organizados 16 .

Por fim, mas não mesmo importante, analisou-se também os depoimentos dos estudantes ao final da disciplina, ao responderem a seguinte pergunta: "Para vocês, como foi o processo de aprendizagem decorrente da construção do MC coletivamente durante o semestre letivo? Destaque as fragilidades e potencialidades identificadas". As respostas foram registradas no diário de classe dos pesquisadores.

Este estudo é parte do projeto desenvolvido no PRODUS - Programa de Inovação em Docência Universitária da Universidade Federal de Viçosa, que foi aprovado pelo Comitê de Ética em Pesquisa protocolo 091/2010, em consonância com o disposto na Resolução 466/2012 do Conselho Nacional de Saúde do Brasil.

\section{Resultados}

Os achados deste estudo, demonstrados pela análise documental (registro nos portfólios pelos grupos) e pelos depoimentos dos estudantes em sala de aula (Quadro 1), informam que de entre os fatores que motivaram os estudantes a construírem o MC, destacam-se as seguintes categorias: facilita o aprendizado das temáticas abordadas na disciplina; propicia a conexão entre os 
ISSN 2179-6750

diversos conteúdos; promove a compreensão dos conceitos chave sobre as Políticas de Saúde em geral e sobre o SUS em específico; estimula o pensamento crítico-reflexivo; propicia o exercício do trabalho em equipe; estimula a criatividade; promove o exercício da capacidade de análise e síntese; estimula o desenvolvimento da autonomia e do empoderamento; e, torna o estudo dinâmico.

Quadro 1. Percepções dos estudantes relatadas nos Portfólios coletivos e depoimentos em sala de aula sobre o processo de construção do MC na disciplina Políticas de Saúde

\begin{tabular}{|c|c|}
\hline $\begin{array}{l}\text { FACILITA O APRENDIZADO DAS } \\
\text { TEMÁTICAS ABORDADAS NA } \\
\text { DISCIPLINA }\end{array}$ & $\begin{array}{l}\text { "Achei bom porque ajuda a estudar e compreender as temáticas de } \\
\text { Políticas de Saúde" } \\
\text { "Muito bom porque exercitamos de várias formas e várias vezes os } \\
\text { conteúdos, ai facilita pois aprendemos fazendo" }\end{array}$ \\
\hline $\begin{array}{l}\text { PROPICIA A CONEXÃO ENTRE } \\
\text { OS DIVERSOS CONTEÚDOS }\end{array}$ & $\begin{array}{l}\text { "Ajuda na capacidade de conectar as coisas (...)" } \\
\text { "Gostei, pois ajuda a gente a juntar tudo o que se estuda e interligar } \\
\text { os diferentes conteudos" } \\
\text { "Aprendemos a relacionar o que aprendemos, um capítulo do livro } \\
\text { tinha ligação com o outro" }\end{array}$ \\
\hline $\begin{array}{l}\text { PROMOVE A COMPREENSÃO } \\
\text { DOS CONCEITOS CHAVE SOBRE } \\
\text { AS POLÍTICAS DE SAÚDE EM } \\
\text { GERAL E SOBRE O SUS EM } \\
\text { ESPECÍFICO }\end{array}$ & $\begin{array}{l}\text { "Elencar termos chave ajuda a associar, e quando você associa } \\
\text { melhora o entendimento sobre as Políticas e sobre o SUS" } \\
\text { "Na disciplina Políticas de Saúde, a construção do mapa conceitual } \\
\text { foi de suma importância, pois aprendemos a identificar os conceitos } \\
\text { chave, facilitando assim o aprendizado" }\end{array}$ \\
\hline $\begin{array}{l}\text { ESTIMULA O PENSAMENTO } \\
\text { CRÍTICO-REFLEXIVO }\end{array}$ & $\begin{array}{l}\text { "Nos estimulou a exercitar o pensamento crítico-reflexivo" } \\
\text { "A construção do MC nos ajudou a desenvolver a capacidade de } \\
\text { analisar, refletir e sistematizar os conceitos importantes sobre as } \\
\text { Politicas de Saúde e o SUS" }\end{array}$ \\
\hline $\begin{array}{l}\text { PROPICIA O EXERCÍCIO DO } \\
\text { TRABALHO EM EQUIPE }\end{array}$ & $\begin{array}{l}\text { "Construir o MC nos ajudou a exercitar o trabalho em equipe e } \\
\text { aprender a lidar com as diferenças" } \\
\text { "Tivemos que aprender a respeitar o tempo do outro, ouvir e } \\
\text { conversar até chegar a um consenso sobre o que colocar no MC e } \\
\text { como construir as sínteses coletivas em cada capitulo estudado" }\end{array}$ \\
\hline $\begin{array}{l}\text { PROMOVE O EXERCÍCIO DA } \\
\text { CAPACIDADE DE ANÁLISE E } \\
\text { SÍNTESE }\end{array}$ & $\begin{array}{l}\text { "Aprendemos a selecionar o que era mais importante, analisar e } \\
\text { fazer as sínteses, e a cada capítulo e conteúdo novo, fomos nos } \\
\text { aprimorando" } \\
\text { "Primeiro fazíamos as sínteses individuas, apresentávamos para os } \\
\text { colegas do grupo e discutíamos até chegarmos a um consenso para } \\
\text { a construção das sinteses coletivas" }\end{array}$ \\
\hline $\begin{array}{l}\text { ESTIMULA O } \\
\text { DESENVOLVIMENTO DA } \\
\text { AUTONOMIA E DO } \\
\text { EMPODERAMENTO }\end{array}$ & $\begin{array}{l}\text { "Com a construção do MC fomos nos apropriando gradativamente } \\
\text { dos conteúdos estudados e aprendemos a estudar por conta própria, } \\
\text { conectando as temáticas com mais autonomia" } \\
\text { "Aprendemos a interpretar e entender melhor o mundo a nossa volta } \\
\text { e refletir sobre as notícias divulgadas sobre o SUS" }\end{array}$ \\
\hline $\begin{array}{l}\text { TORNA O ESTUDO MAIS } \\
\text { DINÂMICO }\end{array}$ & $\begin{array}{l}\text { "Estamos tendo a oportunidade também de aprender o conteúdo de } \\
\text { uma forma mais dinâmica e interessante, e o MC propiciou isto" } \\
\text { "A construção do MC, apesar de trabalhosa, tornou nosso estudo } \\
\text { mais significativo e dinâmico" }\end{array}$ \\
\hline
\end{tabular}

Em relação aos fatores que desmotivaram os estudantes a construírem o MC, destacam-se a dificuldade referente ao manuseio do programa (CMapTools) e o fato de este demandar tempo para sua construção. Outros fatores relatados foram: a dificuldade de identificar os conceitos chave e/ou termos de enlace e de interligar os conteúdos, fatores estes que gradativamente, à medida que o 
ISSN 2179-6750

grupo ia se familiarizando com o MC e a forma dinâmica de estudar a disciplina, foram diminuindo de importância.

Referente às etapas de avaliação do processo de construção do MC pelos discentes, em 3 momentos específicos ao longo do semestre letivo, ocorreu uma avaliação do processo e produto (MC em sua etapa específica, conforme a fase de estudo que se encontrava a disciplina de Políticas de Saúde). Nestes momentos, os estudantes enviaram o MC por e-mail aos docentes, e estes corrigiram e deram feedback com orientações sobre as fragilidades, fortalezas e potencialidades, delineando e discutindo com os grupos os próximos passos a serem seguidos (Figuras 2, 3 e 4).

A figura 2 refere-se à versão 1 do $\mathrm{MC}$ apresentado pelos grupos, ou seja, após serem devidamente orientados pelos docentes em sala de aula (momento presencial) e exercitarem coletivamente (em momentos presenciais e à distância). Nesta primeira versão, como era de se esperar, observou-se alguns equívocos no MC, já que os estudantes ainda estavam aprendendo a manusear o programa CMapTools e iniciando o processo de aprendizado de Políticas de Saúde em geral e do SUS como política de saúde brasileira. Além disso, as equipes ainda estavam se conhecendo e aprendendo a lidar com as diferenças, passo inicial para se formar como grupo. Nesta versão 1, pode-se identificar a ausência de direção entre os conceitos chave e termos de enlace, e o uso exagerado de conceitos considerados secundários na elaboração do MC (identificados com um "X" na correção pelos docentes).

Figura 2. Primeira versão do MC construído na disciplina Políticas de Saúde

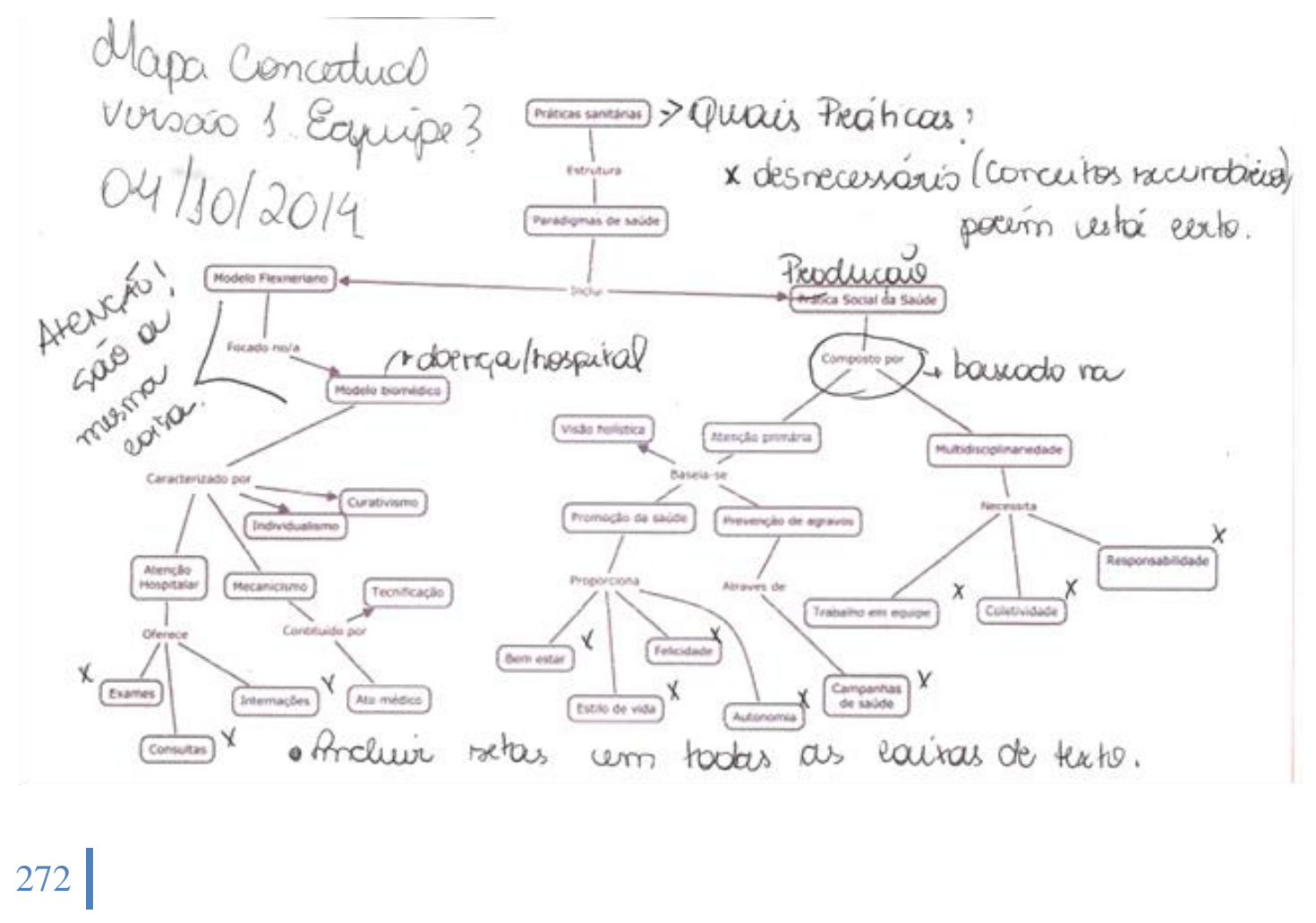


ISSN 2179-6750

Seguindo o processo de aprendizado significativo com estímulo à autonomia e empoderamento dos estudantes, enfoque este esperado com o uso do MC na disciplina de Políticas de Saúde, pode-se observar pela figura 3, representativa do segundo momento de avaliação do MC, que a orientação contínua, rotineira e longitudinal pelos docentes, tanto em sala de aula (momentos presenciais) como à distância (momentos não presenciais), estimulou os grupos a estudarem a partir de objetivos bem delineados, resultando em uma maior apropriação dos conceitos, pressupostos e diretrizes das Políticas de Saúde em geral e do SUS em específico.

Figura 3. Segunda versão do MC construído na disciplina Políticas de Saúde mapa conceitual - Gersä́o 2 - EQUIPE 3 12/11/14

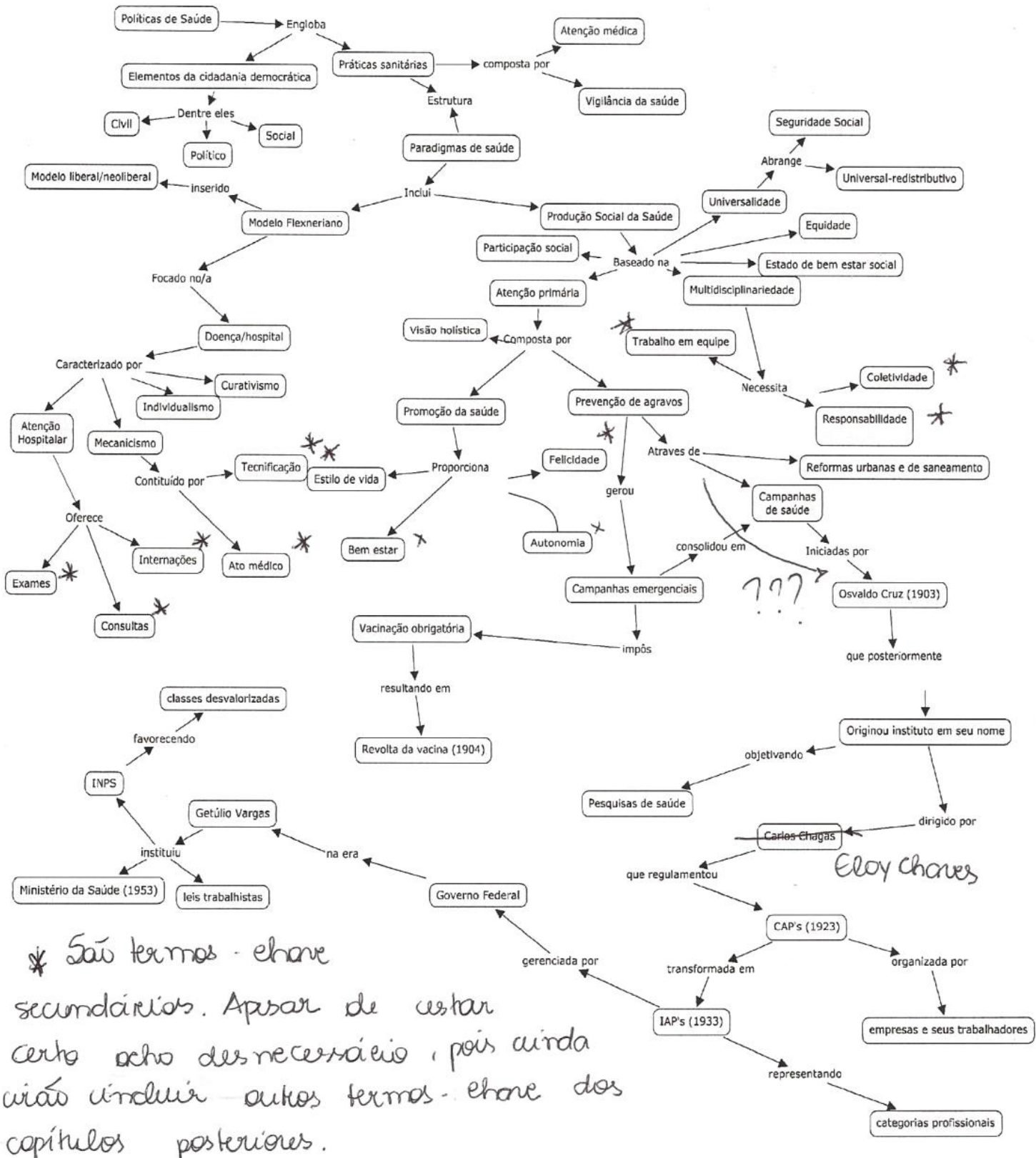


ISSN 2179-6750

Verifica-se um aumento no conteúdo do MC comparado à versão 1, bem como uma nítida ampliação da temática trabalhada, com o uso de conceitos que obedecem a uma coerência na escolha, empregados em sequência lógica (por exemplo, produção social da saúde $\rightarrow$ atenção primária $\rightarrow$ prevenção de agravos). O MC adquire um contorno mais horizontal-ascendente, em vez de exclusivamente vertical-descendente, demonstrando um avanço no processo de incorporação dos conteúdos da disciplina, bem como na apropriação da ferramenta CMapTools.

Por sua vez, pela análise da versão 3 do MC (Figura 4), verifica-se um avanço no domínio do processo de construção pelo grupo. Ou seja, pode-se observar uma maior harmonia estética e espacial (design/organização do MC), bem como uma redução de termos secundários apresentados em relação às versões anteriores, além de um aperfeiçoamento do uso dos termos de enlace e conceitos chave e maior facilidade no manuseio do programa CMapTools - o aprender fazendo.

Figura 4. Terceira versão do MC construído na disciplina Políticas de Saúde

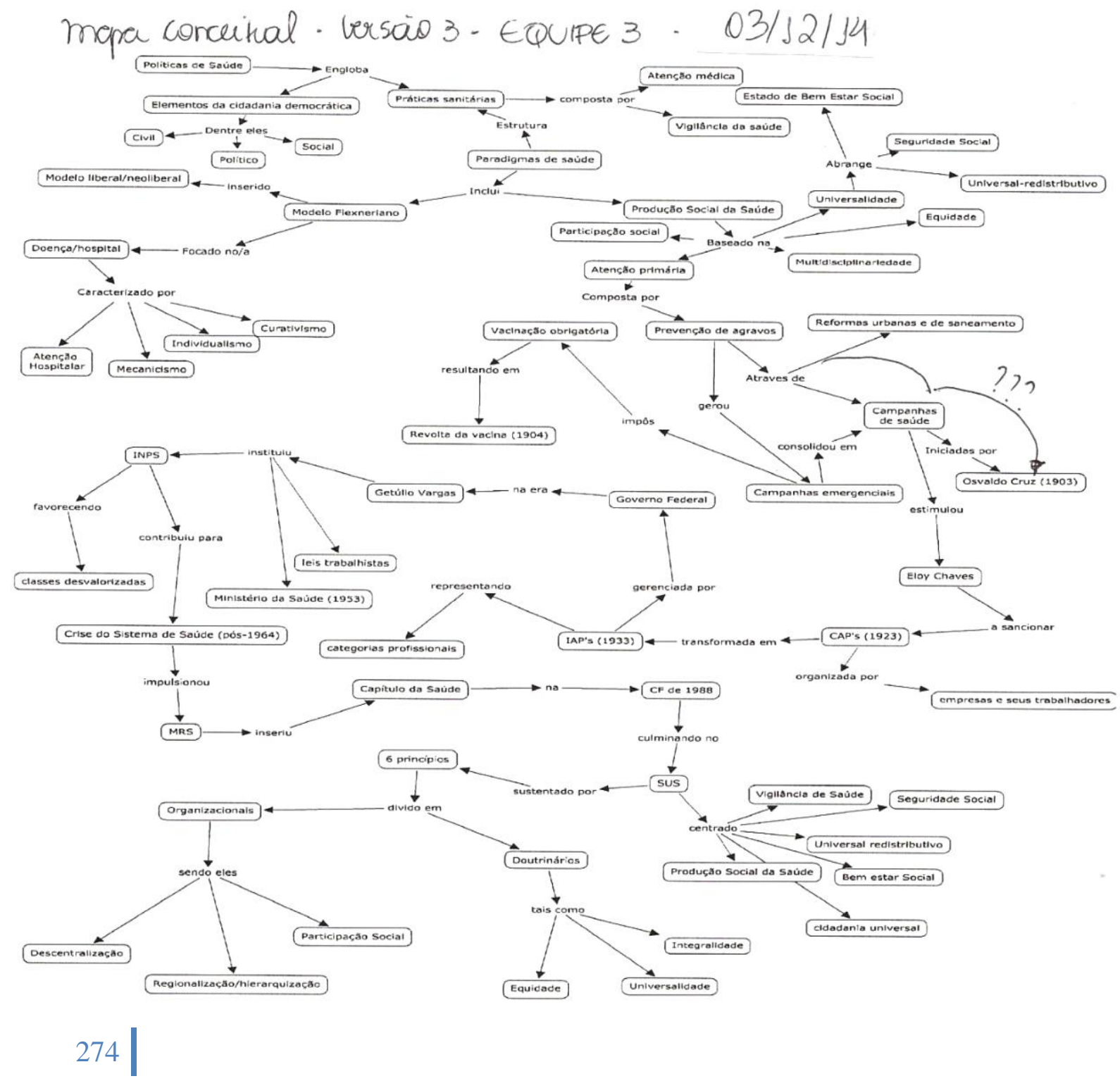


ISSN 2179-6750

Isto tudo foi possível também devido aos arranjos que os grupos foram fazendo para conseguirem desenvolver o trabalho em equipe conforme pactuado no início do semestre - o exercício do aprender a conviver e trabalhar juntos. $\mathrm{O}$ resultado foi a mudança de atitudes e o exercício de habilidades e conhecimentos (competências) com a apropriação dos conceitos e pressupostos importantes para o entendimento das Políticas de Saúde e por consequência do SUS, enquanto política universal, equitativa e integral, importante estratégia de seguridade social do povo brasileiro, fruto das conquistas e bandeiras levantadas pelo Movimento da Reforma Sanitária.

Por fim, ressalta-se que segundo depoimentos dos estudantes ao final do semestre letivo, o exercício crítico com autonomia e responsabilidade ao longo do desenvolvimento da disciplina Políticas de Saúde, resultou no empoderamento e entendimento destes sobre seus papeis como cidadãos e acadêmicos da área da saúde, futuros profissionais e gestores do SUS, missão esta que deve ser posta em prática pela universidade atual, ou seja, estimular os estudantes a exercitarem suas criatividades e capacidade de pensar, saindo do modelo de educação mecânica e alienante.

\section{Discussão}

Os achados deste estudo informam que o MC configurou-se como uma importante ferramenta de ensino, aprendizagem e avaliação, uma vez que, a sua construção possibilitou o desenvolvimento do pensamento crítico e reflexivo, da autonomia e do empoderamento, propiciando a compreensão dos conhecimentos essenciais sobre as Políticas de Saúde em geral e sobre o SUS, em específico, além do exercício do trabalho em equipe.

A fundamentação conceitual do $\mathrm{MC}$ é a teoria da aprendizagem significativa. A aprendizagem significativa pressupõe que aprender é mais fácil quando estão disponíveis na estrutura cognitiva do indivíduo conceitos prévios, que atuam como pontos de ancoragem. Assim, quando conceitos novos se relacionam a conceitos preexistentes do aprendiz, geram alterações na estrutura cognitiva daquele que aprende, mudando os conceitos preexistentes e formando novas ligações entre eles. Por isso, a aprendizagem significativa é permanente e eficaz, enquanto a aprendizagem desvinculada de um contexto de significado é facilmente esquecida e não é prontamente aplicada em novas situações de aprendizagem ou solução de problemas ${ }^{8,9}$.

Nesse sentido, a partir das experiências vivenciadas pelos estudantes, pode-se inferir que o MC demonstrou favorecer o processo de aprendizagem significativa na disciplina de Políticas de Saúde, propiciando a apreensão dos conceitos pelos estudantes e a conexão entre os conteúdos abordados. Como a construção do MC foi dinâmica, os estudantes necessitaram ler continuamente os diversos conteúdos para procurar respostas para as dúvidas que surgiam, o que possibilitou a 
ISSN 2179-6750

elaboração eficaz de significados sobre os conhecimentos, habilidades e atitudes apreendidas, facilitando e reforçando a aprendizagem (Quadro 1). Estes achados vão ao encontro do estudo desenvolvido por Bondía ${ }^{17}$, o qual ressalta que as pessoas que só trabalham a ciência e a técnica são concebidas como sujeitos técnicos, ao contrário, os sujeitos críticos, armados de distintas estratégias reflexivas, dão sentido ao que são e ao que acontece, dimensões estas exercitadas durante a construção do MC.

Para a construção do MC, além da importância de exercitar o pensamento crítico, também é necessário o exercício pelas equipes de trabalho da capacidade de análise, de síntese, de seleção das informações e da criatividade ${ }^{18}$.

No presente estudo, o exercício da capacidade de análise, de síntese e de pensamento críticoreflexivo ocorreu de forma contínua, progressiva e longitudinal. Os estudantes foram estimulados a compreender e fazer conexões entre os conteúdos estudados em todos os momentos da disciplina, ou seja, os conteúdos apresentados no início desta se conectavam aos conteúdos subsequentes, e no final, pôde-se visualizar a organização de forma criativa, de todo o conteúdo da disciplina Políticas de Saúde em um único MC (Figuras 2, 3 e 4). Sendo assim, pode-se inferir que o MC facilitou a atuação dos estudantes como sujeitos ativos de seu próprio processo de aprendizagem, que buscam, selecionam, lêem, analisam, refletem, apreendem e constroem seus conhecimentos ${ }^{5,19,20}$.

Estas evidências destacadas no presente estudo, coincidem com os trabalhos desenvolvidos por Sutherland \& Katz ${ }^{21}$ e Wang et al. ${ }^{22}$, que salientam o potencial do MC para ampliar o processo de ensinar, aprender e avaliar. Para desenvolver a habilidade de construir o MC e representar o conhecimento, os estudantes precisam compreender o conteúdo para se tornarem capazes de desenvolver autonomamente o seu processo de aprendizagem. Nesta perspectiva, o MC atua como uma ferramenta que facilita a educação formativa a partir do momento que permite aos estudantes atuarem como agentes de seu próprio processo de construção da aprendizagem, com autonomia para realizar suas buscas, reformulando suas ideias e apresentando-as de forma crítica e reflexiva, bem como abrindo espaços de liberdade para criar e recriar.

O MC caracteriza-se ainda como uma metodologia ativa que favorece a transformação de uma prática mecanicista e fragmentada em uma prática inovadora e crítica, pois, como verificado no presente estudo, coloca a todo momento o estudante em situação de reflexão sobre a temática abordada. Estudos sobre metodologias ativas e inovadoras que enfocam o aprendizado significativo, ressaltam a necessidade da sociedade contemporânea de investir em uma formação de profissionais crítico-reflexivos, propiciando assim, a ruptura de estruturas acadêmicas positivistas, mecanicistas e 
ISSN 2179-6750

alienantes, que desprivilegiam a dialética e o educando como sujeito proativo de seu processo de aprendizagem ${ }^{4,5,17,23}$.

Neste contexto, no presente estudo pôde-se evidenciar durante o processo de construção do MC o exercício de duas dimensões importantes: a liberdade e a autonomia dos estudantes no contexto de trabalho em equipe. Segundo os estudos desenvolvidos por Sen ${ }^{24}$ e Freire ${ }^{25}$, a autonomia deve ser conquistada e adquirida a partir de decisões, de vivências e pela própria liberdade de escolha. Assim, a autonomia, além da liberdade de pensar por si e da capacidade de guiar-se por princípios que concordem com a própria razão, envolve a capacidade de realizar, o que exige uma atitude de ser consciente e ativo. Sen ${ }^{24}$, ao discorrer sobre o desenvolvimento como liberdade, apresentou dois elementos importantes: a capacidade, que representa as possíveis combinações de potencialidades e situações que uma pessoa está apta a ser ou fazer, e a funcionalidade que representa as várias coisas que esta pessoa pode de fato fazer. Estas dimensões só podem ser adquiridas pelos sujeitos se estes se tornarem aptos a fazer suas próprias escolhas e se responsabilizarem por suas decisões. Assim, durante o processo de construção do MC no semestre letivo, os estudantes gradativamente foram se empoderando e conquistando a autonomia, aprendendo a conhecer, criticar e argumentar sobre o SUS e suas conquistas, sucessos, divergências e contradições (Quadro 1).

Segundo Noguero ${ }^{19}$, as instituições formadoras não têm privilegiado em seus processos educativos o desenvolvimento dos eixos aprender a conviver e trabalhar juntos, focando seus processos de ensino-aprendizagem essencialmente nos aspectos técnicos, o aprender a fazer. À medida que se entende que a educação deve focar no desenvolvimento integral do ser humano, preparando-o não só para o mundo do trabalho, mas também para a vida, ressalta-se a necessidade de incorporação de estratégias pedagógicas inovadoras, que operem sobre essas lacunas, contribuindo para a formação de indivíduos em todas as suas dimensões ${ }^{4,5}$.

Os depoimentos e a análise dos MC dos estudantes em seus vários momentos mostraram que esta ferramenta permitiu aos alunos aprender a conhecer, através das leituras dos capítulos do livro texto e de outros textos referentes aos conteúdos abordados, de forma crítica e reflexiva, da elaboração de sínteses (individuais e coletivas) e da conexão dos conteúdos, por meio da construção do MC, da utilização do programa CMapTools e da criatividade necessária para apresentar todo o conteúdo da temática das Políticas de Saúde em um único MC; e aprender a conviver e a trabalhar juntos, uma vez que os MC foram construídos em equipe.

Os depoimentos dos alunos (Quadro 1) sinalizaram o potencial que o MC possui, propiciando o exercício do trabalho em equipe, a aproximação e cumplicidade do grupo, exercício 
ISSN 2179-6750

de respeito ao outro e de escuta qualificada, isto é, a competência aprender a conviver e trabalhar juntos. No trabalho em equipe, o importante é transformar os conflitos em experiências positivas, levando ao crescimento individual e coletivo. A indução de mudanças no eixo de formação dos profissionais de saúde requer a articulação de saberes e práticas pautados sobre orientações sociais, que respeitem a diversidade, a formação ética, humanística e valorize a integração de saberes e a articulação destes com a realidade vivida ${ }^{26}$.

Outro ponto importante refere-se à pertinência da avaliação formativa, o que favoreceu tanto a aprendizagem do conteúdo como da construção do $\mathrm{MC}$, permitindo que os estudantes desvelassem os conhecimentos adquiridos (Figuras 2, 3 e 4). O MC é considerado uma ferramenta de avaliação formativa quando possibilita uma aprendizagem pautada no feedback professor-aluno e aluno-aluno, desenvolve o exercício de competências respeitando o ensino em diferentes contextos, focando em resultados centrados no processo, e não na forma pontual e quantitativa utilizada nas avaliações tradicionais ${ }^{4,5}$.

Souza \& Boruchovitch ${ }^{9}$ destacaram que, a avaliação formativa, na medida em que explicita o estágio de aprendizagem do estudante, orienta as ações e intervenções docentes no aperfeiçoamento do ensino e na ampliação da aprendizagem. Assim, avaliar formativamente é comprometer-se com o encaminhamento do estudante para percursos que lhe permitam avançar na compreensão de novos conceitos, aperfeiçoamentos dos conceitos prévios e superação das dificuldades de aprendizagem.

A utilização do MC como estratégia de ensino e aprendizagem e, concomitantemente, como ferramenta avaliativa, assume o compromisso com a promoção de experiências educativas que provoquem reflexão e busca de compreensão relativamente aos conceitos ainda em construção, até porque o erro passa a configurar-se como indicador diagnóstico a ser interpretado para orientar ações destinadas à promoção de superações e avanços ${ }^{9}$. A análise da construção dos MC (Figuras 2 , 3 e 4) evidenciou o desenvolvimento gradativo da construção coletiva do conhecimento - pouco a pouco e a cada avaliação dos MC pelos docentes (3 avaliações ao longo do semestre letivo), os estudantes iam se transformando, passando de uma postura mais tecnicista e individualista para uma atitude mais crítica-reflexiva e coletiva.

Não obstante, como obstáculos relativos à construção do $\mathrm{MC}$, encontrou-se a dificuldade referente ao uso do programa (CMapTools) e o tempo a ser dedicado, o que vai de encontro a outros estudos que avaliaram positivamente a utilização do CMapTools, enfatizando a praticidade do programa em relação à construção manual do $\mathrm{MC}^{27}$. No presente estudo, os estudantes utilizaram o programa CMapTools pela primeira vez, o que pode ter contribuído para esta dificuldade. 
ISSN 2179-6750

Em suma, a construção do MC ao longo do semestre letivo estimulou a reflexão sobre o referencial teórico e sobre a discussão e argumentação dos grupos de trabalho sobre questões referentes às políticas de saúde com ênfase no SUS. Segundo Cotta et al. " : "[...] utilizar metodologias ativas e inovadoras significa apostar em uma educação que desenvolva processos críticos de ensino-aprendizagem, que desperte a criatividade e se baseie nela, que apresente as situações como problemas a resolver; ou seja, uma formação que se aproxime tanto quanto possível da vida real".

\section{Considerações finais}

Pelos achados deste estudo, encontrou-se que o processo de ensino e aprendizagem vivenciado pelo coletivo de estudantes a partir da construção dos $\mathrm{MC}$, facilitou o aprendizado e a compreensão dos conceitos chave das temáticas relacionadas às Políticas de Saúde, com ênfase no SUS. Além disso, propiciou a conexão entre os diversos conteúdos de forma crítica e reflexiva, estimulando o trabalho em equipe, com autonomia.

Durante o processo de construção do $\mathrm{MC}$, os estudantes gradativamente foram se empoderando, aprendendo a conhecer, criticar e argumentar sobre o SUS e suas conquistas, sucessos, divergências e contradições, exercitando a competência do aprender a aprender $e$ a conhecer.

Os depoimentos dos alunos apontam para o potencial que o MC possui, propiciando o exercício do trabalho em equipe, a aproximação e cumplicidade do grupo, exercício de respeito ao outro e de escuta qualificada, isto é, a competência aprender a conviver e trabalhar juntos.

Outro ponto importante refere-se à pertinência da avaliação formativa propiciada pelo MC, cuja aprendizagem e avaliação ocorreu de forma longitudinal e pautou-se no feedback professoraluno e aluno-aluno, desenvolvendo o exercício de competências e focando em resultados centrados no processo, e não na forma pontual e quantitativa utilizada nas avaliações tradicionais.

\section{Referências}

1. Cotta RMM, Silva LS, Lopes LL, Gomes KO, Cotta FM, Lugarinho R, et al. Construção de portfólios coletivos em currículos tradicionais: uma proposta inovadora de ensinoaprendizagem. Cien Saude Colet. 2012; 17(3):787-796.

2. Brasil. Ministério da Educação. Diretrizes Curriculares Nacionais. Resolução $n^{\circ}$ 3, de 20 de junho de 2014. Institui Diretrizes Curriculares Nacionais do Curso de Graduação em Medicina e dá outras providências. Brasília; 2014. 
ISSN 2179-6750

3. Delors J. La educacion encierra um tesoro. Madrid: Santillana; 1996.

4. Cotta RMM, Mendonça ET, Costa GD. Portfólios reflexivos: construindo competências para o trabalho no Sistema Único de Saúde. Rev Panam de Saúde Pública 2011; 30(5):415-421.

5. Cotta RMM, Costa GD, Mendonça ET. Portfólio reflexivo: uma proposta de ensino e aprendizagem orientada por competências. Cien Saude Colet. 2013a; 6:1847-1856.

6. Gomes AO, Dias-Colelho UC, Cavalheiro PO, Siqueira-Batista RS. O papel dos Mapas Conceituais na Educação Médica. Rev. Bras de Educ Med. 2011; 36(2):275-282.

7. Novak JD. The theory underlying concept maps and how to construct them. Pensacola [Internet] 2008 [cited 2014 Dec 15]. Available from: http://cmap.ihmc.us/Publications/ ResearchPapers/TheoryUnderlyingConceptMaps.pdf.

8. Ausubel DP, Novak JD, Hanesian H. Psicologia Educacional. Rio de Janeiro: Interamericana; 1980.

9. Souza NA, Boruchovitch E. Mapas Conceituais: estratégias de ensino/ aprendizagem e ferramenta avaliativa. Educação em Revista 2010; 26(3):195-218.

10. Yin R. Estudo de caso: planejamento e métodos. 2a ed. Porto Alegre: Bookman; 2001.

11. Cotta RMM, Campos AAO, Mendonça ET, Costa GD, Machado JC, Silva LS, et al. Políticas de Saúde: desenhos, modelos e paradigmas. Viçosa, MG, Brasil: UFV/Abrasco; $2013 b$.

12. Lopez-Pastor VM. Evaluación Formativa y Compartida em Educación Superior: propuestas, técnicas, instrumentos y experiencias. Narcea S.A. de Ediciones; 2009.

13. Depresbiteris L. Diversificar é preciso...: instrumentos e técnicas de avaliação de aprendizagem. São Paulo: Editora Senac São Paulo; 2009.

14. Lizarraga MLSA. Competencias cognitivas en educación superior. Madrid, Espana: Narcea Ediciones; 2010.

15. Gil AC. Como elaborar projetos de pesquisa. São Paulo: Atlas; 2010.

16. Bardin L. Análise de Conteúdo. 70 ed. Lisboa; 2008.

17. Bondía JL. Notas sobre a experiência e o saber de experiência. Rev Bras Educ. 2002; 19.

18. Wilgis M, Mcconnell J. Concept mapping: an educational strategy to improve graduate nurse critical thinking skills during a hospital orientation program. J. Contin. Educ Nurs. 2008; 39(3):119-26.

19. Noguero FL. Metodologías participativas em la enseñanza universitária. 2a ed. Madrid: Narcea, S.A. Ediciones; 2007.

20. Zabalza MA. Competencias docents del profesorado universitario - Calidad y desarrollo 280 
ISSN 2179-6750

professional. 2a ed. Madrid, Espanha: Narcea S.A. Edciones; 2009.

21. Sutherland S, Katz S. Concept mapping methodology: A catalyst for organizational learning. Elsevier. Evaluation and Program Planning 2005; 28:257-269.

22. Wang WM, Cheung CF, Lee WB, Kwok SK. Self-associated concept mapping for representation, elicitation and inference of knowledge. Elsevier. Knowledge-Based Systems $2008 ; 21: 52-61$.

23. Daley BJ, Torre DM.Concept maps in medical education: an analytical literature review. Medical Education 2010; 44:440-448.

24. Sen AK. Desenvolvimento como liberdade. São Paulo: Companhia das letras; 1999.

25. Freire P. Pedagogia da Autonomia: Saberes necessários à prática educativa. São Paulo: Paz e Terra; 1996.

26. Ferreira MLSM, Cotta RMM, Lugarinho R, Oliveira MS. Construção de espaço social unificado para formação de profissionais da saúde no contexto do Sistema Único de Saúde. Rev. Bras. de Educação Médica 2010; 34(2):304-9.

27. Cogo ALP, Pedro ENR, Silva ASS, Specht AM. Avaliação de mapas conceituais elaborados por estudantes de enfermagem com apoio de software. Texto e Contexto Enferm. 2009; 18(3):482-8. 